Friederike Schröder / Michael Waibel, Hamburg

\title{
Urban governance and informality in China's Pearl River Delta
} Investigating economic restructuring in Guangzhou

\begin{abstract}
Against the background of current economic upgrading trends in China's so called "factory of the world", the Pearl River Delta, this paper adopts an analytical urban governance perspective to investigate the role of informality in urban affairs. In the wake of dynamic economic and urban growth coinciding with rising environmental and social issues, local governments increasingly re-orientate their urban development strategies and apply flexible modes in responding to these challenges. The main hypothesis of this paper is that informality in particular is used as a tool of flexibility and that experimental policies as typical characteristics of the transitional process in China are widely applied nowadays to attract knowledge-intensive and service-oriented industries as well as a highly educated, and presumably creative, workforce. The hypothesis is validated by empirical research analyzing governance processes in development and locational policies of Guangzhou Science City.
\end{abstract}

Keywords: urban governance, informality, economic restructuring, Guangzhou. Pearl River Delta

\section{Introduction}

The Pearl River Delta (PRD) as the "factory of the world" and frontrunner of China's reform and opening process witnesses a new phase in the gradual transition process. Immense efforts have been done to move from a mere focus on growth and spatial expansion towards restructuring of the existing urban fabric and the cities' economic base. There is a policy shift away from labor-intensive production towards higher value-added manufacturing and service industries and to a more knowledge-based economy in general. This has been going on for some years already, but gained substantial impetus due to the global financial crisis, which can be seen as an important catalyst for economic restructuring and upgrading in the PRD region. The growth of the tertiary and quarternary sectors calls for constant economic and urban redevelopment processes and adaptation strategies that allow for different spatial economic entities to be attractive for companies and the global as well as the domestic workforce.

Economic restructuring and changing urban development strategies entail the thesis that these transformations also bring about a change in ur- ban governance modes or the way a city or urban area is governed. Therefore, the underlying assumption is that a diversifying society, and particularly the ongoing economic restructuring process in the PRD, require new formal and informal institutional arrangements, i.e. changing modes of urban governance and specific sets of stakeholder coalitions. We presume that in this process informality, understood here as a mode rather than a sector (ROY/ALSAYAD 2004), is increasingly used as a tool of flexibility, testing, and learning, whereas informality - used as a substitute to fill institutional gaps in the early phase of transition - has diminished over time in the course of the reform process.

Economic restructuring implies a re-production of space. In the PRD, it takes place by comprehensive planning approaches loosening the strict division between industrial and urban space, integrating various urban functions and by upgrading the urban fabric intended to raise urban liveability. How is urban space developed and reproduced? And how are locational policies implemented against the background of a changing economic base? These are the main questions to be answered in this paper. They include questions of who is involved in planning 
and implementation and what are the objectives. Following these questions, our overall aim is to analyze urban governance processes in Guangzhou, China. As an analytical tool, the integrated framework of urban governance developed by DiGaETANO/STROM (2003) will be applied and consequently adapted to the Chinese context.

For the case study, Guangzhou Science City (GSC), particularly its physical development and locational policies as a high-tech park and urban environment, have been chosen. The role of informality as potentially flexible device in these processes will be of special interest. As priority project of Guangzhou's municipal government, designed to upgrade the economic structure along the value chain, GSC is an extraordinary example for the interplay of economic upgrading and comprehensive urban development strategies. It is currently one of the most ambitious and prominent urban development projects in the PRD since the construction of flagship high-tech industrial parks has been promoted by the National Development and Reform Commission in 2008 as a key strategy of the regional upgrading of Guangdong province.

The questions and arguments are analyzed and presented in three main parts. The first analyzes economic restructuring in the PRD. The second discusses the concepts of governance and informality and relates both to the context of China. The third section applies our research approach to the case study of Guangzhou Science City and discusses the role of informality in urban governance processes in the field of urban economic restructuring.

\section{Economic restructuring in the Pearl River Delta}

In Europe and North America economic restructuring has mostly been a necessity of the fall of regional economies or declining of industrial centers (HASSINK 2005, 571, FAINSTEIN/ CAMPBell 2002, 6). In China, and particularly in the Pearl River Delta with average yearly GDP growth rates of $14 \%$ between 2000 and 2009 (Tab. 1), rising salaries and living standards, and a fast growth in urban population one can barely speak of a declining region. However, high speed economic and urban development, hastily built-up infrastructure, the superimposition of new and old physical structures, traffic congestion, environmental degradation, spatial fragmentation and social segregation take their toll. These processes call the need for restructuring of the existing urban fabric and economic base.

The PRD has experienced tremendous economic growth and spatial transformation since the late 1970s. It differs from the Yangtze Delta River (YDR) in the way that its economic development and urbanization process is mainly the result of exogenous forces, such as foreign direct investments (FDI), influences from the Chinese diaspora of Hong Kong, Singapore, and other parts of the world, and small to medium-sized labor-intensive processing manufacturing. In contrast, the development pace of the YDR rather results from endogenous dynamisms and agglomeration advantages from the major city of Shanghai (HE et al. 2006, 431). Though dominated by external forces, internal factors - apparently affecting all regions of China - also play a role in the PRD's development, i.e. institutional changes and innovations, fiscal decentralization and fierce inter-urban competition. It is the interdependency of different structural, cultural, and political forces that have unevenly transformed the economic, social, physical and spatial landscapes in the PRD (HE et al. 2006, 436; SHEN 2002, 92) - and transformation is still going on.

Agricultural diversification and industrialization of the 1980s and 1990s gives way to a new phase of economic restructuring with a deliberately induced shift away from labor-intensive manufacturing towards knowledge-intensive industries and a growth of the tertiary sector. "Building a modern industrial system" (NDRC $2008,15)$ is the programmatic device to prioritize the PRD's development of modern service industries (e.g. finance, convention and exhibition services, scientific research and development), modernizing and advancing capital- and technology-intensive manufacturing industries (e.g. automotive, nuclear and wind power equipment), and vigorously develop high-tech industries (biotechnology, pharmaceutical products, new materials, computer, electronic and optical products) (loc. cit.). This new phase of economic restructuring can be dated back to China's accession to the World Trade Organization (WTO) in 2001. The implementation of economic restructuring policies has gained substantial impetus in the wake of the "financial 
tsunami", as the global financial crisis was labeled in the PRD, that has laid off thousands of mostly migrant workers in the labor-intensive industries of textile, toys, and electronic production.

Chinese governments at the national, provincial, and local levels (i.e. municipal and district-level governments) have recognized in recent years that the economic boom of the last three decades caused environmental costs and has raised social exclusion. Thus, there is a tendency away from a mere focus on economic growth towards policies promoting an improved quality of the urban economic and living environment and of social, health, and educational infrastructure.

Recent statements made by party leaders illustrate the political momentum for economic upgrading. For example, Guangdong Communist Party Secretary Wang Yang maintained: "Our growth model of 30 years, which enriched us rapidly, has come to the end of its cycle. ... Our mission is a tough one. We must convince them that we must change. The old ways of consuming resources and importing labor will not work. Even if we wanted to continue with it, we would be unable to do so - we are running out of resources and environmental capital." And the Guangzhou Party Secretary Zhu Xiao- dan argued in a similar way: "We've paid a heavy price for rapid growth. (...) We will support companies at the high end of the value chain and use industrial parks as a driving force." (KuHN 2009a-e) The deeper meaning of these quotations becomes clear when one considers the latest ideological framework formulated by the Communist Party of China (CPC) in 2003. In order to adapt and adequately cope with economic and socio-political challenges on the one hand as well as to maintain supreme authority and political legitimacy on the other, the CPC offers rather vague, but formative ideological guidelines phrased under the concept of "Socialism with Chinese characteristics". Under this framework, Hu Jintao, General Secretary of the CPC and President of the PRC, has been promoting a new approach to developement, i.e. the "scientific development concept". The stated idea behind this concept and behind scientific development is to "take people as the main thing, establish a concept of comprehensive, coordinated, sustainable development, and promote comprehensive economic, social, and human development" (FEwSMITH 2004, 3). Hence, "scientific development" is ultimately to lead to the construction of a "harmonious society" and will thus officially change China's focus from mere economic growth to promoting economic, social, and environmental development (HEBERER/SCHUBERT 2008，203;

Tab. 1: GDP growth and per capita GDP in the Pearl River Delta and its two major cities Guangzhou and Shenzhen

2000

2005

2006

2007

2008

2009

Pearl River Delta (total)

GDP growth (compared

to previous year, \%)

Per capita GDP

(in Chinese Yuan)

20,280

40,336

47,241

55,048

63,065

67,407

Guangzhou

GDP growth (compared

to previous year, $\%$ )

13.3

12.9

14.9

15.3

12.5

11.7

Per capita GDP

(in Chinese Yuan)

25,626

53,809

63,184

72,123

81,941

89,082

Shenzhen

GDP growth (compared

to previous year, \%)

15.7

15.1

16.6

14.8

12.1

10.7

Per capita GDP

32,800

60,801

69,450

79,645

89,587

92,772

(in Chinese Yuan)

Source: Guangdong Statistical Yearbook 2010 
SCHOON 2011). Evidently, those slogans are still underfed with a great deal of propaganda, but the implementation of economic restructuring policies can be certainly regarded as an essential step towards an economy that is less polluting and offers a higher quality of life.

Trickled down to the provincial level, the new guiding principle has led to the most important cornerstone of economic upgrading and restructuring in the PRD, the "Plan for the reform and development of the Pearl River Delta (20082020)" issued by the National Development and Reform Commission in December 2008 (SCHRÖDER/WAibel 2010,2). Its main aim is to build up a maturing industrial system by prioritizing the development of modern service industries, as well as vigorously speeding up the development of advanced manufacturing with a focus on high-tech development. The plan promotes to substantially increase "gross domestic expenditure on research and development" (GERD) investments. Embedded into the central government's initiatives such as the Eleventh Five Year Plan for National Economic and Social Development of PR China or the Program for Mid- and Long-term Development of Science \& Technology (2006 to 2020) this means an envisaged increase of research and development (R\&D) intensity to $2.5 \%$ of GDP until 2020' (loc.cit.).

With regard to this paper's question of how urban spaces are developed and locational policies are implemented against the background of economic restructuring, a very important and often underestimated factor of relevance for China's rapid and constantly high economic growth over the last 30 years is the pragmatic and flexible experimental approach. It has been introduced by the post-Mao regime to test economic reforms in distinct spatial entities first and, in the case of success, extend them to other regions in the country. In the Western conventional understanding, legislation takes place in advance of implementation. In China (and in other transitional countries such as Vietnam), the mode of testing or experimenting and therefore implementation before formal legislation has proved a pragmatic tool in this rapidly changing and highly heterogeneous spatial, structural, and socio-economic environment (LIN 2001, 387; NG/TANG 2004, 181). Reformer Deng Xiaoping famously characterized this experimental approach as "groping the stones while crossing the river". Experimental forms of gov- ernance mostly include the informal testing of strategies or tools before formalizing them. The Pearl River Delta region is a perfect showcase for this experimental strategy.

This has also wider implications in terms of urban governance. As our research shows, the development of Guangzhou Science City (GSC) is accompanied by a high flexibility and experimental character that involves a change in the relationship between private companies and the local state. This change became necessary because state officials needed to cooperate with private companies to achieve their predetermined development goals. Before going into the case study, we will have a closer look at the concepts of urban governance and informality illustrating their value for analyzing economic restructuring and the reproduction of space in Guangzhou.

\section{Narrowing the understanding of urban governance and informality}

Governance is an ambiguous concept developed from a discourse mainly in North America and Western Europe. It deals with socio-economic interdependencies that have been changing since the late 1970s (JeSSOP 1995, 309; KoOIMAN 2005, 150; MAYNTZ 2005, 13). It emphasizes that the idea of the state as key actor in political decision-making, its exclusive responsibility for fulfilling state functions and duties, as well as its influence on the economy and society is increasingly changing. This often implies a shift in understanding of political processes away from government towards governance. Whereas government denotes decision-making that lies solely within the state and its institutions, governance refers to altered interrelations between state, society, and the economy and the increasing importance of less directive forms of political regulation (cooperative and non-hierarchical), e.g., political coordination or negotiation in networks (PIERRE/Peters 2000, 12).

Can such an admittedly fuzzy concept, stressing the increasing role of non-hierarchical forms of regulation, help to understand highly state-controlled processes in urban China? The authors believe that this question must be answered in the affirmative. First of all, the emergence of the governance paradigm stands for the adoption of a wider analytical perspective in political science. Secondly, it is maintained that understanding it as an analytical concept (rather than as 
manifestation of a postulated changed global reality) (PIERRE 2005, 451ff.) can create an awareness of structures and processes influencing policymaking that would otherwise be overlooked. Processes describe what actors can do, i.e., regulation (via incentives or hierarchical command) or coordination (BENZ et al. 2007, 16; PIERRE/ PETERs 2000, 22). Structures are understood here as institutional contexts in which actors are able to operate (hierarchies, markets, networks, communities, associations). This allows analyzing how regulation and coordination occur within a defined policy field, such as economic restructuring, or in a spatially distinguished area. With regard to China's gradual transition process and its highly dynamic urban development processes serving as arena for current economic upgrading processes, this analytical governance approach helps to entangle the complex forces underlying urban affairs in China.

\section{Urban governance}

In comparative urban politics, governance is conceived as a coordination process of political decisions in the urban and economic spheres. Derived from the structural perspective of political economy, it is based on the notion that governing procedures at the national, regional, and local levels; market forces; and economic as well as social structures set the context of urban governance (DiGaEtano/Strom 2003, 362). However, an exclusively structural approach often lacks an encompassing consideration of the complex set of influences and processes in urban affairs, such as cultural impacts as well as the different actors and stakeholders involved. This is particularly problematic in China, which is influenced, among other aspects, by a long tradition of cultural factors and the influential role of powerful leaders (such as Mao Zedong or Deng Xiaoping). The significant deficiency of single-level explanation is surmounted by the comprehensive approach of DIGAETANO/STROM (2003), the biggest advantage of which is the integration of three middle-range theories, i.e., structuralism, culturalism, and rational choice. With its merit as integrative analytical tool, this approach will be subject to our analysis of go-

Fig. 1: Integrative model of urban governance

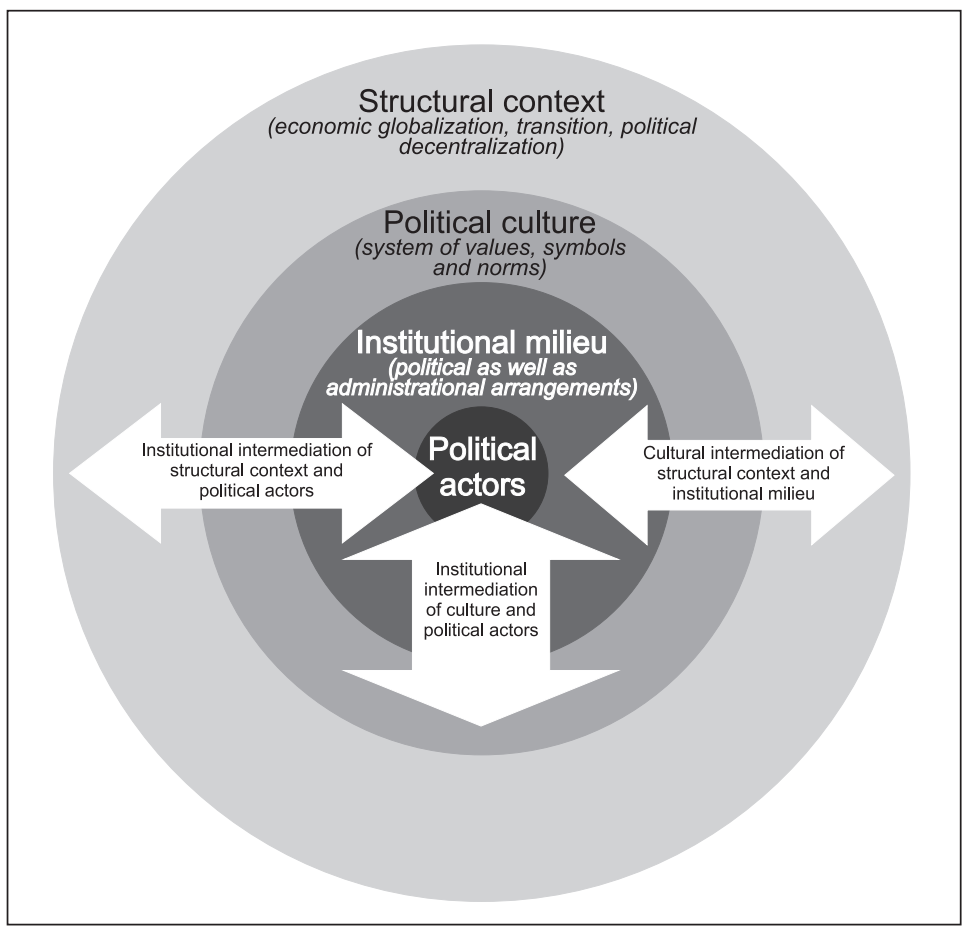

Source: DigaETANTO/STROM 2003, 372; modified 
verning structures in terms of economic restructuring in Guangzhou.

DiGaETANo/STROM (2003) have highlighted the importance of each approach, structural, cultur$\mathrm{al}$, and rational-choice, as well as their dynamic interdependencies. Therefore, they have endeavored to integrate all three into a single framework. As an outcome, three interrelated levels of analysis are identified: (1) The structural context (e.g. political decentralization, transition, economic globalization) frames political decision-making, including over time; (2) political culture (beliefs, values, symbols) gives meaning to political organization and decisionmaking'; and (3) political actors who attempt to influence governmental decision-making in ways that benefit themselves and the interests they represent. In this context, political actors include all actors participating in urban governance processes, i.e., public as well as private and social actors or stakeholders. The three spheres of analysis trickle down to influence the institutional milieu, understood as the set of all formal and informal institutions that moderate the different analytical spheres and are crucial for their integration (Fig. 1).

\section{The role of informality}

Informality plays a crucial role when looking at governance processes, since it is evident that no political system, not even in the liberal democracies of Western Europe, functions solely on the basis of formal structures and processes (DANIELS 2004). Decision-making or political systems are not only the sum of formal institutional structures, but a mixture of formal and informal institutions (DiGAETANO/STROM 2003, 363). We understand institutions (both formal and informal) with regard to the work of NORTH (1990: 3) as "rules of the game in a society or $[\ldots]$ the humanly devised constraints that shape human interaction".

Informality in urban and economic development processes takes place within a complex set of relationships between different actors, regulations, and ways of decision-making. It is thus understood here as interaction-related institution defining informality according to social or economic interaction. This interaction-related informality is associated with "contractual relationships between different individuals or organizations (tiers of government may be among them, but do not embody the state as producer of legal norms)" (Altrock et al. 2008, 5). It describes all forms of political activities that are not traceable and laid down in written documents. These may be debates and discussions that find consideration in decision-making processes beyond a legal framework as well as all interaction between individuals and organizations, that accompany planning processes or contracts, but are not written down. Interaction-related informality can contribute to mutual understanding without explicit interaction and thus reduce complexity while enhancing flexibility (loc. cit.).

Despite a seemingly clear distinction between formal and informal constraints, no single political procedure can be characterized as being of either formal or informal character altogether (KIRCHBERGER 2004, 10). Thus, informality is not necessarily contradictory to formal processes or official rules, neither should it be understood as a deviation from the norm (i.e., formal institutions). Close and complex links between and overlaps of formal and informal spheres exist in all political systems. This makes it rather difficult to distinguish clearly between formal and informal (loc.cit. 11), a factor that has to be kept in mind when investigating decision-making processes. Governance analysis reveals the specific strength of the formal-informal modes of a political system, as well as their interrelations, which shed light on the „real function“ (KÖLLNER 2005, 27) of a political system and are therefore of eminent importance for analysis. To understand how a city is governed with its different policies and strategies can only be understood when both formal and informal rules and negotiations are analyzed (loc.cit.; see also KIRCHBERGER 2004).

\section{Informality - part of the game in the Pearl River Delta}

In the Pearl River Delta (PRD), a very active state has been experimenting with flexible deregulation within rigid institutional settings since the start of the reform process more than 30 years ago. As a result, informality is constantly being produced, which underlines RoY's $(2009,826)$ argument that informality is located within the scope of the state rather than outside of it. Though formal political institutions mature and become increasingly effective, informality remains robust and important in Chinese socioeconomic politics (FUKUI 2000). However, informal institutions, like any socio-economic 
phenomenon, have changed and have been transformed over time and space (ALTROCK 2012; FUKUI 2000, 13; WAIBEL 2008).

The prominence of informality in China is closely related to the country's political culture. Thus, one rather conventional explanation why informal institutions are so pervasive in China is suggested by PyE (1985): "In most situations, whether in the party, the bureaucracy, or in nongovernmental institutions such as schools and factories, too many people are waiting in line for advancement and too few options exist for the formal procedures to do the job of selection. Therefore everyone must prudently seek guanxi ties [...]. Within the Chinese bureaucracy the formal regulations tend to be overly constrictive, producing cumbersome procedures and little effective action. [...] hence the informal structures of power built through the guanxi networks often serve as the most effective way of getting the state's business done." In such a context, informality is mostly attributed to excessive state regulations (Roy/AlSAYYad 2004, 13). Doubtlessly, the fact that the PRD has one of the most complex administrative systems in the world with multiple jurisdictions is conducive to such kinds of informality (ENRIGHT et al. 2005, 233).

A more comprehensive analysis of specific Chinese informal institutions made by social scientists over the last three decades has revealed a multiplicity of factors explaining their origin (KIRCHBERGER 2004, 17), including:

- The particular cultural path of institutions based on the Confucian tradition and the political culture formed by the socialist revolution. One example of the historical continuities is the duality between the formal Confucian respect for thoughtful, selfless, and public-minded manners on the one hand and the self-seeking, interest-driven, and exchange-mediated behavior in actual life on the other.

- The importance of interpersonal relationships, so-called guanxi. Political influence is applied through subtle, culturally sanctioned behavior by way of exchanges of favors and repayment of commitment (FUKUI 2000, $15 \mathrm{f}$.$) .$

- There is a lack of a rule-of-law tradition.
- The closely interlinked party-state structure, which creates structural latitude. It is characterized by the parallel party-state structure, which allows for and encompasses diverse and often opaque linkages between vertical and horizontal lines of authorities (HEBERER/ SCHUBERT 2004; HeILMANN 2004).

However, the list might be arbitrarily continued. What is distinctive in the way informality is used in China is that there is an amalgamation of formalities and - importantly - a pragmatic use of informal relationships. Informality will most likely not disappear altogether. On the contrary, it is the way in which informality is practiced that changes over time.

Apparently, the Chinese state and its local representatives at various levels engage in an ambiguous set of practices concerning the role of informality. ALTROCK/SCHOON (2009) coined the term "conceded informality" for this phenomenon. The term emphasizes the pro-active state that tolerates informal practices where they are functional (see also WAIBEL 2008; 2009; WAIBEL/GRAVERT 2009). This cooptation of informal structures to serve formal government has a long tradition in China. Conceded informality seeks to abandon the dichotomy between formal and informal. LEAF (2005) speaks of cooperative governance between formal and informal structures, for example. The extent to which informality is tolerated, used, or promoted depends on a variety of determinants such as the power of the state to formulate regulations and policies; the availability of resources in the public sector; global, national, and regional economic competitiveness; and global influences on socio-cultural aspects. Specific patterns and attitudes dealing with informality in China, and in the PRD in particular, have been identified by Altrock/Waibel (2010) and SCHOON (2010):

- The state "fights" informality, when its major political objectives are threatened.

- The state "tolerates" informality, when it serves development.

- The state "promotes" informality, when it produces new strategic knowledge.

- The state "utilizes" informality, when flexible guiding principles serve as political strategy. 
This listing shows that the state and its local representatives take a tactical approach in using their position as rule-setters. For example, they may accept informal bottom-up initiatives and subsequently formalize them, e.g., as an adequate response to newly emerging problems or niches, or they can forbid them and, as a consequence, ban informal institutions. Another more simple reason for informality in the PRD can be the lack of state power to efficiently filter through all spheres of institutions, markets, and society from the very beginning of the transitional process (Altrock/WaIBEL 2010, 12).

The role of informality in China has wide implications for urban governance, hence the way economic restructuring and the accompanied reproduction of urban areas. Flexible and experimental, testing and learning arrangements are expected to being applied by local state and private (i.e. companies) actors for the implementation of economic restructuring policies.

\section{Changing urban governance in the Pearl River Delta}

In China, urban governance is characterized by a high degree of state, especially local government, control in urban policies (NG/TANG 2004, 175). Since the implementation of market reforms in the late $1970 \mathrm{~s}$, the central government does no longer exercise an all-embracing topdown control over economy and society (Chan/Hu 2004, 10; NG/TANG 2004, 175; XU/ WANG 2002, 250). In fact, economic, administrative, and fiscal decentralization has taken place throughout China since the start of the reform process, although politically, there has been no significant sign of devolution (CHIEN $2008,3)$. The combination of new market elements and decentralized state apparatus has offered abundant flexibility especially for local governments in pursuing extrabudgetary revenues to facilitate entrepreneurialism in urban development (Wu 2002, 1075). Though still strong, the predominant role of the central state has been softened in many aspects of urban change, new players from the private sector appeared in shaping the urban landscape. The prevalent mono-player arena has changed towards a multiplayer arena with multifaceted interactions of central and local governments, domestic and foreign investors and businesses ( $\mathrm{HE}$ et al. 2006, 432). All in all, the transition from planned to market economy, the policy of open- ing up and increasing integration into the world market, as well as learning processes and capacity building within the country have directed changes in the control, provision, and coordination mechanisms over time (WUTTKE 2009, 11). In other words, the gradual implementation of the reform process in China is causing constant change in the "rules of the game". This implies changing governance arrangements, as well.

In particular, local governments, i.e. municipal and urban district governments, have become key actors of economic and urban regulation processes. Increased competition between cities vying to attract companies and investments, but also environmental degradation and social and spatial fragmentation are significant challenges for China's metropolises. This in turn requires the constant adaptation of urban development strategies. The increased importance of local governments and of private companies for overall economic welfare has strengthened their role in decision-making. The autonomy allows them - to a certain degree to undertake independent planning, political decisions, as well as legislative and executive governmental functions. Moreover, despite its function as regulatory instance, the local state authorities have gained responsibility in the promotion of local economic growth and, for the first time, had to apply location policies of their own to lure companies and capital. This forces them to involve stakeholders, their needs and aspirations and thus adapt a demandside approach guiding of their locational policies. How this rather customer-oriented approach is implemented will be shown in the subsequent section of this paper.

The realignment of state, market and society with a changing role of local governments has been explained by different authors as the local state incrementally following the logic of economicentrepreneurial action (cf. "autonomous local governments", LAQUIAN 2005; "local state corporatism", OI 1992, 1995; "entrepreneurial city", JESSOP/Sum 2000; Wu 2002, 2003; Wu et al. 2007; "local developmental state", ZHU 2004).

\section{Case study of Guangzhou Science City}

\section{Methodology}

The integrated framework of urban governance developed by DiGaETANo/Strom (2003) has 
been applied to the case study of the Guangzhou Science City (GSC) development and its locational policies. Concretely, how the reproduction of this urban area and its locational policies are governed in order to enforce economic restructuring is analyzed by looking at the relationships and interactions between different actors and stakeholders in the public and private sectors (governing relations, in the terminology of DiGaetano/Strom), the way decisions are made (governing logic), the impact of key decision-makers, and their political objectives.

The analysis is based on qualitative, semi-structured interviews conducted in 2009 and 2010. Two main groups of interviewees were selected for interviews. The first, stakeholders, consisted of individuals with a potential stake in the development and locational policies of GSC, such as members of governmental bodies, planning bureaus, companies located within GSC, and residents, among them villagers affected by eviction, living in the area of interest; the second, experts, was made up of professionals such as academic staff and planning experts that were not directly involved in locational policies, but have in-depth knowledge regarding the case study. Interviews with experts proofed to be especially valuable for qualifying the wider economic, political context. Altogether, 35 interviews were conducted; of which eleven with experts and 24 with stakeholders. The research is complemented by an intensive review of governmental documents, newspaper articles and scientific literature.

According to our research experience, in China, governance is frequently equated with participation in the realm of civil society. Having been warned that in China, research in the field of governance is often misunderstood as looking for incidences of corruption, we frequently used the term "urban management" doing interviews, particularly when talking to political leaders.

\section{Guangzhou Science City - a symbol of economic upgrading}

Guangzhou Science City (GSC) has been selected as a showcase project, which represents a spatial cluster of the higher value-added sector and stands for the attempt to upgrade the local economy (HE 2006, 205; WANG/HuANG 2007, $18)$. From an analytical governance perspec- tive, its development is rather innovative. In contrast to earlier developments, it is the result of a comprehensive urban development strategy and therefore represents much more than a mere economic entity with high-tech focus: The formerly strict division of industrial and urban residential and commercial areas is loosened. Besides building a new administrative center as well as living area, the entire district, in which GSC is located, has been planned as comprehensive urban environment to become an integral part of the whole metropolis. Moreover, as part of the Plan for the reform and development of the Pearl River Delta (2008-2020) promoting the restructuring of the PRD's economic base, GSC is a very illustrative example for the interplay of economic upgrading and comprehensive urban development strategies.

Located in the eastern part of Guangzhou and comprising a total planning area of nearly 45 $\mathrm{km}^{2}$, GSC constitutes the linchpin of the Guangzhou high-tech industrial development zone (GHIDZ). As part of Guangzhou's Urban development concept plan established in 2000 , the city's east is intended to serve as a center for high-tech development (XU/YEH 2003). The area has been strategically important for Guangzhou's economy since the early 1980s, encompassing four national-level special economic areas (Guangzhou Economic and Technological Development District GETDD, Guangzhou Hi-Tech Industrial Development Zone GHIDZ, Guangzhou Free Trade Zone GFTZ, and Guangzhou Export Processing Zone GEPZ). These economic areas were merged under a single joint administration in 2002 and renamed the Guangzhou Development District (GDD) (SchröDER/WAiBel 2010, 70).

As priority project for economic upgrading along the value chain, GSC is supposed to develop into a flagship high-tech park with a focus on information technology, bioscence, pharmaceutical, and environmental industries. Besides building a new center and a residential area, the area as a whole is planned as a comprehensive urban environment, including the provision of the social, educational, and administrative infrastructure elements required to make it an integral part of the overall city ( $\mathrm{He}$ $2006,205)$. In this regard, it not only serves as a location for the attraction of knowledge-intensive companies, but is also designed to attract a qualified white-collar workforce to work and live in this area. Further, it is anticipated that 
GSC will relieve the core city and contribute to a more polycentric urban development.

Governance in the development phase of GSC The analysis of governing relations, governing logic, political objectives, and key stakeholders in the development of GSC reveals a mode of strongly (local) government-led initiation as well as implementation. However, needs and interests of companies but also of inhabitants have been increasingly considered. This has not taken place via direct participation but in panels and mostly informal exchange where experts, selected elites, and companies take part in. Surveys served to give insights on the needs of local population, which were included in the planning process (TANG et al. 2008; WUTTKE et al. 2010).

Guangzhou municipality and its relevant administrative bodies already initiated the project of GSC in 1998, led the master planning and selected the site. Together with district-level government bodies they were responsible for project implementation. However, key decisions have been finalized by high officials (on municipal and district level), whose personal development visions apparently influenced the planning proposals. A common occurrence in China's urban planning is the involvement of so called experts as consultants from outsourced or privatized urban management research institutes or planning bureaus to aid in shaping the economic reforms (LEAF/Hou 2006; TANG et al. 2008; Wong et al. 2006). Accordingly, Chinese research and planning institutes were directly approached by governing bodies to participate in functional planning and design of the master plans for GSC.

Besides municipal and district planning departments, private and international planning bureaus were allowed to participate in the development process as well. This is a new phenomenon as a result of strategic planning, established in Guangzhou in the year 2000. Strategic planning has emerged as an important tool to respond quickly to the development and control needs of local governments (LEAF/Hou 2006, 569; SCHRÖDER/WAIBEL 2010, 74). It has been arisen from initiatives by local municipal governments supplementing conventional master planning which was considered as static and inadequate to respond to rapid socio-economic and urban spatial change. The Guangzhou Concept Plan 2000 was the first strategic tool for urban development implemented in China (WANG et al. 2001, 5; Wu/ZHANG 2007, 719). This procedure is a perfect example of experimental governance in China. First tested in Guangzhou and subsequently Hangzhou (Concept Plan of Hangzhou), these two plans are now being followed by other cities in China. Strategic planning as it is understood and practiced in China is undertaken to support localized economic targets in line with attracting and

Fig. 2: Changing involvement of key stakeholders during the development process of Guangzhou Science City

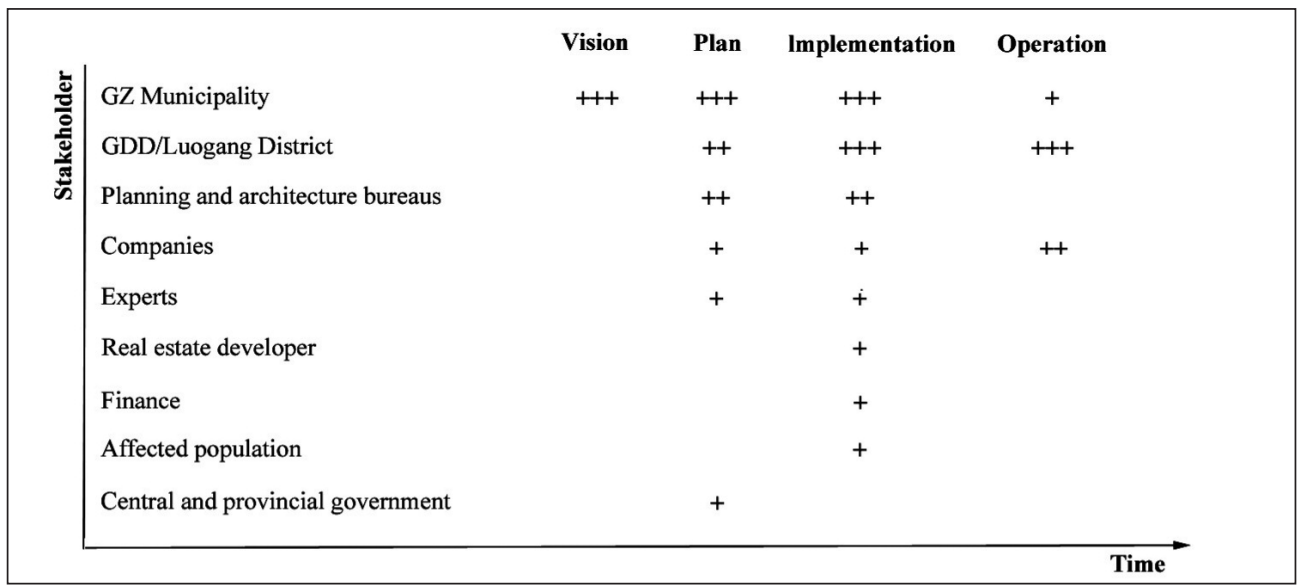

Source: own design 
guiding capital investment. It addresses more flexible aspects of urbanization such as development directions, which are soft, rather vague formulated as future targets in urban development and land use. These directions are beyond what is considered by the physical planning orientation of formal statutory planning (LEAF/ Hou 2006, 569).

Moreover, semi-private or special purpose associations have been involved to take over functions that were formerly the prerogative of the administration; most importantly in the development of GSC these are investment consultancies. They not only served as negotiation part in the realm of the district government when it came to relocation processes of villages located within the planning boundaries. They also have close relationships with companies located in the area. They share believes and experiences with local governments and give suggestions due to their in depth knowledge about companies' and their workforces' needs. Together with the governments' own mostly informal exchanges with companies and with overseas experiences, these suggestions form the basis of decision-making processes in the case of developing GSC. Face-to-face communication, e.g. during regular meetings within companies or symposiums with businesses, is used to learn about changing needs and demands of companies, workforce and inhabitants (mostly white collar). Collected needs and aspirations are condensed and presented to the local People's Congress (PC) and the Chinese People's
Political Consultative Conference (CPPCC) to be discussed and revised. Accordingly, planning strategies are constantly revised and adapted.

In sum, though not formal involved in the development process, non-state actors such as experts, companies and white-collar workforce are apparently indirectly involved building-up informal arrangements with governing bodies and therefore influencing changing urban development strategies (see Fig. 2). However, these informal arrangements are open to a small group of selected people, only. For example, the ordinary population of the villages located within Luogang District has not been included: About 60,000 of them had been relocated in the course of the development of GSC since 2004. However, participation was limited to a survey on their housing conditions undertaken on behalf on the management committee as well as to exclusionary negotiations with the village heads.

All in all, it can be said, that the deliberate use of informal arrangements in the development of GSC served local officials to learn from exogenous experiences via interactions with foreign, returning overseas Chinese, and domestic investors. In this regard, investment, especially foreign direct investment can not only be regarded as a driver for economic growth but also an important channel of knowledge diffusion for changing urban governance processes (Chien/ZhaO 2008). There is a close connection between urban development strategies and locational policies of GSC since the compre-

Fig. 3: Residential-, leisure- and work-spaces in Gouangzhou Science City
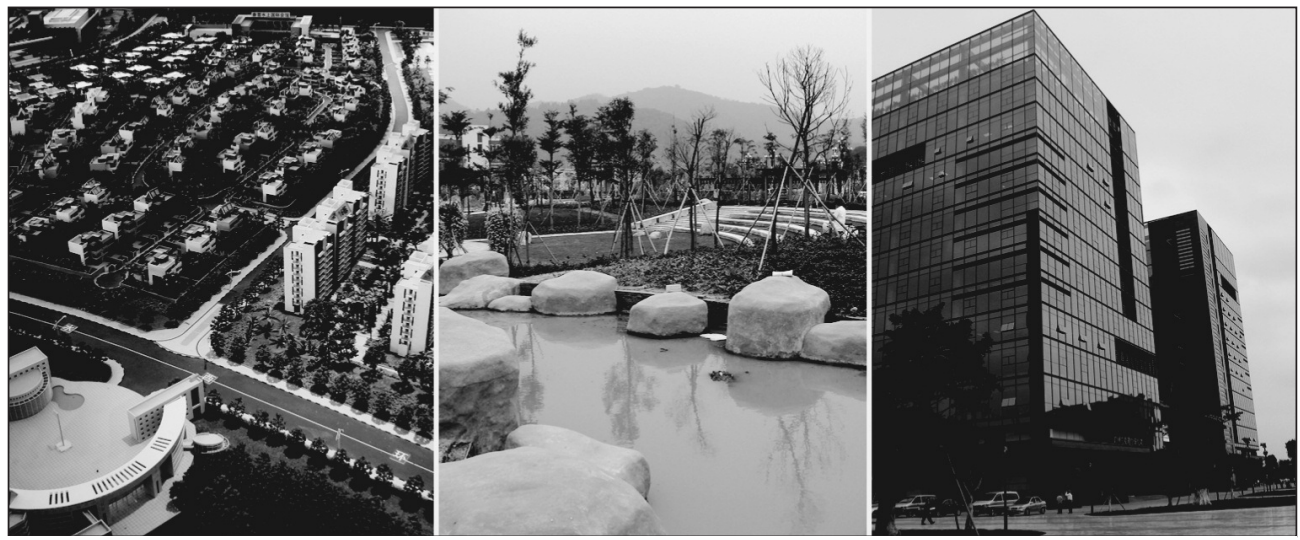

Source: WAIBEL/SCHRÖDEr 2009 
hensive development approach adopted for establishing GSC can be viewed as part of an overall strategy to enhance the area's attractiveness for investors and white-collar people to work and live in GSC.

\section{Locational policies and the role of informality in Guangzhou Science City}

The raison d'être of special economic areas in China is to attract investors and therefore to gain revenues. In times of economic restructuring, it no longer suffices for the management bodies to offer a fenced mono-functional industrial area, as was the case 20 years ago. Nowadays, the message of economic upgrading and advancement along the value chain is the most important driver in locational policies. As a result, clean and liveable urban environments with a lot of greenery and flagship architecture are introduced to a highly competitive market. This is especially true for GSC. Here, locational policies can be seen as an interplay of three important tools: (1) hard incentive schemes; (2) a comprehensive approach in designing the physical outline of the area; and (3) soft incentive schemes. Hard incentive schemes are means from the classical toolbox of economic development and investment attraction. In GSC, these include the provision of technical infrastructure such as roads, gas, electricity, etc., economic incentives such as tax reductions and tax holidays, low or no land use fees, including discounted rentals, low energy costs, and physical infrastructure such as an incubator center for start-up companies to rent out lab and office space or a special funding program for attracting start-up companies.

GSC is planned for development into a comprehensive urban area. It is intended that "urban liveability" and "quality of life" will be created by the integration of various urban functions specifically, housing, education, leisure and amenities, and generous provision of greenery and space in general (Fig. 3). The simple assumption behind this new approach in regard to the physical outline of GSC is that the more qualified (white-collar and presumably creative) workforce working in knowledge-intensive companies and living in the area is expected to have different needs and aspirations concerning the urban environment than lowerqualified (blue-collar) people working in laborintensive industries.

Eventually, soft incentive schemes are formed around different informal, flexible, and trustbuilding services provided by the zone management and semi-private or special purpose associations such as investment consultancies. In GSC, these include openness regarding information policies towards companies, pragmatism, service orientation, and particularly network promotion activities. The latter encompasses various different layers of communication between companies, between companies and organizations (e.g., chambers of commerce, investment consultancies), and between companies and the government that serve to enhance relationships and knowledge diffusion. This mainly takes place in informal meetings at lunch, dinner, during breaks at conferences or club events such as a yearly golf tournament organized by the Guangzhou Multinational Corporation Club (MNCC). The primary aim of the network promotion activities is to increase communication between companies with the aim of fostering some kind of "innovative milieu". Our research found that this multi-layered, complex net also serves another important purpose: It allows the management body to get information on the needs and aspirations of companies and their workforce. This information gained by interaction-based informality is highly appreciated, because it allows development strategies and location policies to be frequently adjusted in order to remain attractive for the companies. In this respect, learning processes may be understood here as "learning by interacting" (LIEFNER 2008). Such learning processes are evidently crucial drivers for the flexible adaptation of governance processes towards economic restructuring (SCHRÖDER/WAIBEL 2010, 78).

A soft incentive feature that may be less publicized, but was often mentioned during our interviews with companies is the zone management's pragmatism and service orientation. In this context, pragmatism means a flexible approach in dealing with (formal) regularities. A striking example for this is the management body's pragmatic dealing with registration policies. Apparently, enterprises are not necessarily obliged to be physically located within the area of GSC itself. Apparently, it is sufficient just to be classified as a high-tech company by the government to enjoy the zone's preferential policies. Furthermore, the zone management of GSC has a high reputation for its service orientation, efficiency, and professionalism, and tries to resolve any issues arising for companies 
within a few days. Further services include training courses for start-up companies in the fields of business development, tax regulations, and acquisition of financial support. Apparently, the specific, increasingly institutionalized interaction between management body and the companies over time in the area of GSC has contributed to - in terms of SCHAMP $(2003,151)$ - time- and space-specific institutional arrangements that rest on path dependencies but at the same time have the potential of establishing new structures for action.

Our research reveals that comprehensive urban planning and soft incentive schemes are becoming more and more important in the course of economic upgrading, and that these factors can provide a decisive local advantage in competition with other spatial economic entities. This has been confirmed by interviews with stakeholders and experts. Hard incentive schemes have become increasingly ubiquitous among special economic areas all over China, and have therefore become less significant as a location factor. Anyway, the significance of these zones decreased after China's WTO entry was followed by the gradual reduction of preferential policies and economic incentives. Certainly, the fierce competition between special economic areas has promoted the deliberate use of informal arrangements and therefore higher flexibility regarding the governance of economic entities in China.

\section{Conclusion}

It has been illustrated that the shift from laborintensive towards higher value-added and capital-intensive industries is actively promoted by national, provincial, and local governing bodies in China's "factory of the world", the Pearl River Delta. The upgrading process apparently requires new urban development strategies and locational policies as well as innovative governance constellations. In the tradition of the Chinese transitional process, which is based on experimental approaches, informality is being produced and applied in a flexible way. By analyzing the development of GSC and its locational policies, this paper has argued that interaction-based informality is used as a tool of flexibility as well as of experimental policies attracting knowledge-intensive industries and a highly educated workforce. The pursuit of competiveness and the importance of learning are immanent features of this process. Since hard incentives, such as the provision of a reliable technical infrastructure, are no longer unique selling propositions, new strategies have to be identified as means of distinction. The management body of GSC is applying a wide range of rather informal strategies in its development strategies and location policies. This is apparently happening despite a very clear and highly transparent regulatory framework guiding investments and development procedures.

Thus, the competitiveness of GSC results to a large extent from high flexibility and service orientation towards incoming companies, mostly negotiated in informal interactions. Here, informality as a mode of flexibility serves as a strategy in locational policies to create a local competitive edge. Further, informality is used as tool for testing and learning. The selective involvement of private actors and stakeholders in the development and locational policies of GSC has been cited as an example. So far, this informal procedure has mostly taken place via particularistic and personalized exchanges or, to use the terminology of DiGAETANO/STROM (2003), through a rather clientelistic governance mode. If this approach proves successful in the long run, we may safely expect it to be formalized, and then maybe even to become less selective. This would imply a change of governance mode towards non-exclusive arrangements.

Moreover, the use of informality produces new strategic knowledge in terms of comprehensive urban development as well as in terms of upgrading strategies towards a knowledge-based economy. In this way, the management body of Guangzhou Science City deliberately uses informality as a mode of learning. All in all, we would like to reiterate the important point that it is the hybrid interconnectedness between informal and formal practices that makes the location policies of special economic entities successful. Therefore, simplistic connotations such as that of the formal-informal divide, or the implicit idea of formality as the norm and informality as a deviation from the norm, are obsolete when dealing with current urban realities in China and elsewhere.

Looking at the development of governance and informality over time in the course of China's reform period, it can be stated that in the early stage of the transitional process, status-related 
informality was widely used as an alternative or substitute for an inadequate or lacking legislative framework and non-existing local capacity (subsumed here under the concept of "institutional gaps"). In the further course of the reform period, during the advanced transitional process, however, informality may be more and more regarded as a complement to formal arrangements and to formal ways of interaction (Altrock 2011; Waibel 2009).

Linking governance with the notion of informality reveals the importance of institutions within the complex and highly dynamic urban environment of China's transitional process. In order to add to the picture of urban governance and informality in urban China, research on other policy fields as well as on further spatial and sectoral arenas is no doubt indispensable. Grasping informality in China by means of an analytical governance framework such as the model of DiGaetano/Strom is certainly a challenge. First of all, it has to be reflected whether such a model, developed in a Western context, is appropriate for analyzing informal processes in China. Certainly, this framework has to be adapted to the situation in China. The field research and subsequent application has shown advantageous and disadvantageous aspects. $D i$ Gaetano/Strom's model of urban governance is enticing because of its comprehensive scope, which integrates three middle-range theories, i.e., structuralism, culturalism, and rational choice. But this comprehensive approach calls for the consideration of a multitude of aspects (e.g. structures and processes, culture, institutions, actor-relations) in urban affairs. In this way, it reveals challenges in research that might finally lead to a lack of theoretical and empirical depth. Furthermore, the specific case of China reveals characteristics such as the political system (socialism with Chinese characters), the important role of personal networks (guanxi), the parallel party-state-system, that require particular consideration when analyzing urban governance in China. All of these particularities are difficult to cover using the DiGaetano/Strom model which shows the limits of its applicability.

However, we should highlight the fact that the model also has its merits. For example, its breadth proved to be a distinct advantage, because it helps to embrace complexities in urban affairs. These complexities are due to the plurality and often opaqueness of national, provin- cial, municipal, and even district strategies as well as the multi-faceted relations between the government, the corporate sector, and the emerging civil society, to name but a few challenges. The model grasps the major and complex influences affecting urban affairs. Each approach alone would not be sufficient for mapping the dynamic interdependencies and interrelations between structures (and processes), culture, and actors. At the same time, the model reduces the fuzziness of concepts such as governance and informality, whose ambiguous nature is certainly a challenge regarding conceptualization and empirical operationalization. Also, aspects of temporality are included within the framework, particularly in the structural context layer. These merits are especially important for analyzing urban governance within the highly dynamic urban environment of transitional China.

\section{Notes}

1 In comparison, the average GERD (gross domestic expenditure on R\&D) in the European Union in 2007 was $1.8 \%$, in Germany and Japan $2.5 \%, 3.5 \%$ respectively.

2 The division between informal institutions and political culture is often misleading. In this respect, we propose to follow the understanding of KIRCHBERGER $(2004,11)$. According to her, all observable regular but not formally codified behavior patterns that apply to interaction between different actors are considered "informal institutions". In contrast, behavior patterns that are not directly observable, internalized moral concepts, and individual socializations are considered "political culture" (ibid.). Following this line of argumentation, the widespread guanxi as the traditional network of personal relations in China would be related to political culture whereas a not formalized negotiation process over political affairs would relate to informal institutions.

\section{References}

Altrock, U. (2012): Conceptualizing informality: Some thoughts on the way towards generalization. In McFarlane, C./ Waibel, M. (Eds.): Urban Informalities: Reflections on the Formal and Informal. Farnham. (forthcoming).

Altrock, U./Pillath, C.-H./Waibel, M. (2008): Governance over time: Spatial Differentiation and temporal change of urban development and redevelopment in a context of multiple transitions and informal growth in the PRD. DFG Priority Programme 1233: "Megacities Megachallenge: Informal Dynamics of Global Change". (Unpublished research project proposal). 
Altrock, U./Schoon, S. (2009): The Governance of Urban Regeneration in Southern China. Liverpool. (Paper presented at the AESOP Conference, 15-18 July 2009, Liverpool, UK).

Altrock, U./WAiBel, M. (2010): The governance of spatial and economic restructuring. Informal dynamics of the maturing mega-city. DFG Priority Programme 1233: "Megacities-Megachallenge: Informal Dynamics of Global Change". (Unpublished research project proposal).

BenZ, A./LÜTZ, S./SchimanK, U./Simonis, G. (2007): Einleitung. In: dies. (Hrsg.): Handbuch Governance. Theoretische Grundlagen und empirische Anwendungsfelder. Wiesbaden, 9-26.

Chan, R. C. K./Hu, Y. (2004): Urban governance. A theoretical review and an empirical study. In: Asian Geographer, (23)1-2, 5-18.

ChIEN, S.-S. (2008): Urban/regional governance, Chinese style. A perspective of asymmetric decentralization. Berlin. (International Essay Competition and Workshop on ,Collective Identities, Governance and Empowerment in Megacities“, Urban Planet Conference Series organized by the Irmgard-Coninx-Foundation in cooperation with the Humboldt-University and the WZB, 11th16th June 2008, Berlin).

DANIELS, P.W. (2004): Urban challenges: the formal and informal economies in megacities. In: Cities, (21)6, 501511.

DiGaetano, A./Strom, E. (2003): Comparative urban governance. An integrated approach. In: Urban Affairs Review, (38)3, 356-395.

Enright, M. J./Scott, E. E./ ChANG, K.-M. (2005): Regional powerhouse. The Greater Pearl River Delta and the rise of China. Singapore.

FAINSTEIN, S./CAMPBELl, S. (2002): Introduction. Theories of urban development and their implications for policy and planning. In: Fainstein, S./Campbell, S. (Eds.): Readings in urban theory. Malden a.o., 1-15.

Fewsmith, J. (2004): Promoting the scientific development concept. In: China Leadership Monitor, Summer 2004, (11), 1-10.

FukUI, H. (2000): Introduction. On the significance of informal politics. In: Dittmer, Li/ Fukui, H./ Lee, P.N.S. (Eds.): Informal politics in East Asia. Cambridge a.o., 119.

Guangdong Statistical Yearbook (2010): National economic accounts. Internet: http://www.gdstats.gov.cn/tjnj/ e3.htm (3. 8. 2011).

HAssinK, R. (2005):0 Guest editorial: The restructuring of old industrial areas in Europe and Asia. In: Environment and Planning A, (37), 571-580.

He, S./Li, Z./Wu, F. (2006): Transformation of the Chinese city, 1995-2005. Geographical perspectives and geographers' contributions. In: China Information, (20)3, 429-456.

He, Y.-G. (2006). Guangzhou Science Park. An ideal place for "Two Suitable". The planning and experience in construction management of Guangzhou Science Park. In: National Territorial Construction Bureau of Guangzhou Development District (Ed.): 20 years in
Guangzhou Development Zone. Guangzhou, 204-214 (Chinese).

Heberer, T./Schubert, G. (2008): Politische Partizipation und Regimelegitimität in der VR China. Band I: Der urbane Raum. Wiesbaden.

HeIlmann, S. (2004): Das politische System der Volksrepublik China. Wiesbaden. (2. Aufl.)

JESSOP, B./Sum, N.-L. (2000): An entrepreneurial city in action: Hong Kong's emerging strategies in and for (inter)urban competition. In: Urban Studies, (37)12, 2287 2313.

JESSOP, B. (1995): The regulation approach, governance and post-fordism. Alternative perspectives on economic and political change? In: Economy and Society, 24(3), 307-333.

Kirchberger, S. (2004): Informelle Regeln der Politik in China und Taiwan. Hamburg.

KoOIMAn, J. (2005): Governing as governance. In: Schuppert, G.F. (Hrsg.): Governance-Forschung. Vergewisserung über Stand und Perspektiven. Baden-Baden, 149-172.

Kunn, R. (2009a): Guangdong. Re-envisioning Guangzhou. Internet: http://www.businessweek.com/ globalbiz/content/jul2009/gb2009076_009429.htm (12.4.2010).

KuHN, R. (2009b): Guangdong visions. A talk with Wang Yang. Internet: http://www.businessweek.com/ globalbiz/content/jun2009/gb2009065_691758.htm (12.4. 2010).

KuHN, R. (2009c): Guangdong visions. Forging China's future.Internet:http://www.businessweek.com/globalbiz/ content/aug2009/gb2009084_539590.htm (12.4. 2010).

KuHN, R. (2009d) Guangdong visions. Responding to the crisis. Internet: http://www.businessweek.com/ globalbiz/content/jun2009/gb20090615_39380.htm (12.4. 2010).

KuHN, R. (2009e) Guangdong visions. The way forward. Internet: http://www.businessweek.com/globalbiz/ content/oct2009/gb2009101_302976.htm (12.4. 2010).

LAQuian, A. A. (2005): Beyond metropolis. The planning and governance of Asia's mega-urban regions. Washington D.C./Baltimore.

LEAF, M. (2005): Modernity confronts tradition. The professional planner and local corporatism in the rebuilding of China's cities. In: Bishwapraya, S. (Ed.): Comparative Planning Cultures. New York, 91-111.

LEAF, M./Hou, L. (2006): The "Third Spring" of urban planning in China: The resurrection of professional planning in the post-Mao era. In: China Information, (20)3, 553-585.

LIEFNER, I. (2008). Ausländische Direktinvestitionen und internationaler Wissenstransfer nach China. In: Geographische Rundschau, (60)5, 4-11.

LIN, G. C. S. (2001): Metropolitan development in a transitional socialist economy. Spatial restructuring in the Pearl River Delta, China. In: Urban Studies, (38)3, 383-406.

MAYNTZ, R. (2005): Governance Theory als fortentwickelte Steuerungstheorie? In: Schuppert, G.F. (Hrsg.): 
Governance-Forschung. Vergewisserung über Stand und Entwicklungslinien. Bd. 1. Baden-Baden, 11-20.

NDRC (National Development and Reform Commission) (2008): The outline of the plan for the reform and development of the Pearl River Delta (2008-2020). Internet: http://en.ndrc.gov.cn/ (5.8. 2009)

NG, M. K./TANG, W.-S. (2004): Theorising urban planning in a transitional economy. The case of Shenzhen, People's Republic of China. In: Town Planning Review, (75)2, 173-203.

NoRTH, D. C. (1990): Institutions, institutional change, and economic performance. Cambridge/New York.

OI, J. C. (1992): Fiscal reform and the economic foundations of local state corporatism in China. In: World Politics, (45)1, 99-126.

OI, J. C. (1995): The role of the local state in China's transitional economy. In: The China Quarterly, 144, 1132-1149.

Pierre, J. (2005). Comparative urban governance. Uncovering complex causalities. In: Urban Affairs Review, (40)4, 446-462.

Pierre, J./Peters, B. G. (2000): Governance, politics and the state. New York.

Pye, L. W. (Ed.)(1985): Asian power and politics. The cultural dimension of authority. Cambridge, MA.

Roy, A./ AlSAyyad, N. (2004): Prologue/dialogue. Urban informality. Crossing borders. In: Roy, A./AlSayyad, N.: Urban informality. Transnational perspectives from the Middle East, Latin America and South Asia. Lanham/Lexington, 1-6.

Roy, A. (2009): The 21st-century metropolis. New geographies of theory. In: Regional Studies, (43)6, 819-830.

SchAmp, E. W. (2003): Raum, Interaktion und Institution. Anmerkungen zu drei Grundperspektiven der deutschen Wirtschaftsgeographie. In: Zeitschrift für Wirtschaftsgeographie, (47)3-4, 145-158.

ScHOON, S. (2010): Governability, borders and urban citizenship. Part: Governability. Kassel. (Unpublished interim report, University of Kassel, Germany).

SCHRÖDER, F./WAIBEL, M. (2010): Urban governance of economic upgrading processes in China. The Development of Guangzhou Science City. In: Internationales Asienforum - International Quarterly for Asian Studies, (41)1-2, 57-82.

SHEN, J. (2002): Urban and regional developement in post-reform China. The case of Zhujiang Delta. In: Progress in Planning, 57, 91-140.

TANG, B.-S./ Wong, S. W./ LAU, M. C. H. (2008): Social impact assessment and public participation in China. A case study of land requisition in Guangzhou. In: Environmental Impact Assessment Review, (28)1, 57-72.

WAIBEL, M. (2008): Mega-urban growth, informality and the issue of governability. Towards theorising specific informal dynamics in a wider context. Berlin. (International Essay Competition and Workshop on „Col- lective Identities, Governance and Empowerment in Megacities“, Urban Planet Conference Series organized by the Irmgard-Coninx-Foundation in cooperation with the Humboldt-University and the WZB, $11-16$ June 2008, Berlin).

WAIBEL, M. (2009): The model of the "Transitional Urban Development Cycle". Explaining complex interrelationships between urban informality, governability, and restructuring policies. Berlin. (Workshop "Urban Development in a Globalising World - Overcoming the Formal-Informal Divide", organized by the Irmgard-Coninx-Foundation in cooperation with the Humboldt-University and the WZB, 12-13 June 2009, Berlin).

Waibel, M./Gravert, A. (2009): B/ordered spaces and social exclusion in Vietnam. Housing conditions of labor migrants in the face of global economic integration. In: TRIALOG - Journal for Planning and Building in the Third World, 101, 39-44.

Wang, M.-H./DuAn, X.-F./TIAN, L. (2001): The practice of concept planning for the City of Guangzhou. In: Focus Report, (25)3, 5-10 (Chinese).

WANG X. L./HuAng, R.-B (2007): The empirical study about Guangzhou's science and technology originality condition. In: Science and Technology Management Research, (5), 15-19 (Chinese).

Wong, S.-W./TANG, B.-S./Horen, B. v. (2006): Strategic urban management in China. A case study of Guangzhou Development District. In: Habitat International, 30, 645 667.

WU, F. (2002): China's changing urban governance in the transition towards a more market-oriented economy. In: Urban Studies, (39)7, 1071-1093.

Wu, F. (2003): The (post-)socialist entrepreneurial city as a state project. Shanghai's reglobalisation in question. In: Urban Studies, (40)9, 1673-1698.

Wu, F./Xu, J./YeH, A. G.-O. (2007): Urban Development in post-reform China - State, market, and space. London, New York.

WutTKE, C./SchröDER, F./XIAO, L. (2010): Contemporary planning issues in a pioneering city. The governance of urban redevelopment in Shenzhen, China. In: Pacific News, (33), 9-12.

WuTTKE, C. (2009): Urban Governance in der Volksrepublik China. In: Geographische Zeitschrift, (97)2-3, 130-150.

Xu, J./Yen, A. G. O. (2003): City profile (Guangzhou). In: Cities, (20)5, 361-374.

Xu, X./WAnG, X. (2002): Characteristics of governance in China - based on the practice in the Pearl River Delta. In: Wong, K.-y./Shen, J. (Eds.): Resource management, urbanization and governance in Hong Kong and the Zhujiang Delta. Hongkong, 249-257.

ZHU, J. (2004): From land use right to land development right. Institutional change in China's urban development. In: Urban Studies, (41)7, 1249-1267. 